\section{(6) OPEN ACCESS}

- Additional material is published online only. To view please visit the journal online (http://dx.doi.org/10.1136/ gutjnl-2016-312529).

${ }^{1}$ NIHR Liverpool Pancreas Biomedical Research Unit, Royal Liverpool University Hospital, University of Liverpool, Liverpool, UK

${ }^{2}$ Department of

Gastroenterology and Hepatology, University Hospital of Santiago de Compostela, Compostela, Spain

${ }^{3}$ Department of Integrated Traditional Chinese and Western Medicine, Sichuan Provincial Pancreatitis Centre, West China Hospital, Sichuan University, Chengdu, China

${ }^{4}$ Department of Pharmacy, University Hospital of Santiago de Compostela, Compostela, Spain

${ }^{5}$ Department of Preventive Medicine and Public Health, University of Santiago de Compostela, Compostela, Spain

\section{Correspondence to} Professor Robert Sutton, NIHR Liverpool Pancreas Biomedical Research Unit, 5th Floor UCD, Royal Liverpool University Hospital, Daulby Street, Liverpool L69 3GA, UK; r.sutton@liverpool.ac.uk

Received 30 June 2016 Revised 6 November 2016 Accepted 18 November 2016 Published Online First 9 December 2016

\section{Linked}

- http://dx.doi.org/10.1136/ gutjnl-2016-313455

\title{
Efficacy of pancreatic enzyme replacement therapy in chronic pancreatitis: systematic review and meta-analysis
}

\author{
Daniel de la Iglesia-García, ${ }^{1,2}$ Wei Huang, ${ }^{1,3}$ Peter Szatmary, ${ }^{1}$ Iria Baston-Rey, ${ }^{2}$ \\ Jaime Gonzalez-Lopez, ${ }^{4}$ Guillermo Prada-Ramallal, ${ }^{5}$ Rajarshi Mukherjee, ${ }^{1}$ \\ Quentin M Nunes, ${ }^{1}$ J Enrique Domínguez-Muñoz, ${ }^{2}$ Robert Sutton, ${ }^{1}$ NIHR Pancreas \\ Biomedical Research Unit Patient Advisory Group ${ }^{1}$
}

\section{ABSTRACT}

Objective The benefits of pancreatic enzyme replacement therapy (PERT) in chronic pancreatitis (CP) are inadequately defined. We have undertaken a systematic review and meta-analysis of randomised controlled trials of PERT to determine the efficacy of PERT in exocrine pancreatic insufficiency (EPI) from CP. Design Major databases were searched from 1966 to 2015 inclusive. The primary outcome was coefficient of fat absorption (CFA). Effects of PERT versus baseline and versus placebo, and of different doses, formulations and schedules were determined.

Results A total of 17 studies (511 patients with CP) were included and assessed qualitatively (Jadad score). Quantitative data were synthesised from 14 studies. PERT improved CFA compared with baseline $(83.7 \pm 6.0$ vs $\left.63.1 \pm 15.0, p<0.00001 ; l^{2}=89 \%\right)$ and placebo $(83.2$ \pm 5.5 vs $\left.67.4 \pm 7.0, p=0.0001 ;\left.\right|^{2}=86 \%\right)$. PERT improved coefficient of nitrogen absorption, reduced faecal fat excretion, faecal nitrogen excretion, faecal weight and abdominal pain, without significant adverse events. Follow-up studies demonstrated that PERT increased serum nutritional parameters, improved GI symptoms and quality of life without significant adverse events. High-dose or enteric-coated enzymes showed a trend to greater effectiveness than low-dose or non-coated comparisons, respectively. Subgroup, sensitive and metaregression analyses revealed that sample size, $C P$ diagnostic criteria, study design and enzyme dose contributed to heterogeneity; data on health inequalities were lacking.

Conclusions PERT is indicated to correct EPI and malnutrition in CP and may be improved by higher doses, enteric coating, administration during food and acid suppression. Further studies are required to determine optimal regimens, the impact of health inequalities and long-term effects on nutrition.

\section{INTRODUCTION}

Chronic pancreatitis (CP) is a progressive fibro-inflammatory disorder with sustained destruction of acinar, ductal and islet cells. ${ }^{1} \mathrm{CP}$ has an annual incidence of $4-12$ per $100000,{ }^{2}$ increasing worldwide. ${ }^{3}$ Aetiologies include environmental toxins (prolonged, heavy alcohol exposure and cigarette smoking), hyperlipidaemia, single and/or

\section{Significance of this study}

What is already known on this subject?

- Chronic pancreatitis (CP) is a major health problem associated with health inequalities, causing intractable abdominal pain, peripancreatic complications, exocrine pancreatic insufficiency (EPI), long-term malnutrition and type $3 c$ diabetes mellitus.

- Pancreatic enzyme replacement therapy (PERT) is administered by some for EPI in CP but the benefits remain to be confirmed.

- No meta-analysis has been conducted previously of randomised clinical trials assessing PERT for EPI in CP, while a previous Cochrane review of PERT in CP was inconclusive.

\section{What are the new findings?}

- This meta-analysis shows that PERT improves the coefficients of fat and nitrogen absorption versus baseline and versus placebo, reducing faecal fat excretion, faecal nitrogen excretion, faecal weight and abdominal pain without significant adverse events. Follow-up studies have found that PERT increases serum nutritional parameters, improves $\mathrm{GI}$ symptoms and quality of life without significant adverse events.

- Although there was significant heterogeneity between trials, subgroup analyses did not alter the findings, and exclusion of trials with small sample sizes $(<40)$ or without imaging and/or histology to establish CP significantly reduced the heterogeneity. Data on health inequalities were sparse but for those on $\mathrm{CP}$ aetiology attributed to alcohol excess.

multiple genetic mutations (PRSS1, SPINK1, CTRC, CASR, CFTR, CLDN2 and CPA1) and autoimmune disease. ${ }^{3}{ }^{4} \mathrm{CP}$ is generally progressive, with marked variation in abdominal pain and GI symptoms. These greatly impair quality of life $(\mathrm{QoL}){ }^{5}$ while exocrine pancreatic insufficiency (EPI) and diabetes mellitus (DM) contribute to the low median 
Significance of this study

\section{How might it impact on clinical practice in the foreseeable future?}

- This systematic review and meta-analysis of 17 randomised trials of PERT for EPI in CP demonstrates the efficacy of PERT for correcting malnutrition in CP. PERT may be optimised by higher doses, enteric coating, ingestion during food and acid suppression.

- Further studies are needed to determine optimal methods to address the impact of health inequalities on PERT for EPI in CP.

survival of $15-20$ years from diagnosis. ${ }^{3} 6$ The prevalence of CP has been estimated at circa 50 per 100000 but this is a significant underestimate in view of incidence and median survival, which suggests $100-200$ per $100000 ;^{3}$ similarly, EPI is probably underestimated. ${ }^{3}$ Not surprisingly the management of $\mathrm{CP}$ and its complications is resource intensive; ${ }^{7}$ were the management of EPI and DM from CP to be improved and complications reduced, these resources would be better spent.

EPI, characterised by inadequate pancreatic secretion of digestive enzymes and bicarbonate, is one of the most significant complications of CP affecting $>50 \%$ of diagnosed patients, ${ }^{8}$ resulting in compromised digestion, absorption and metabolism of nutrients. Severe EPI tends to develop between 5 and 10 years following an initial diagnosis of $\mathrm{CP}^{1}$ and can complicate acute necrotising pancreatitis, cystic fibrosis, DM, pancreatic cancer and following surgery to bypass or resect the duodenum and/or pancreas. ${ }^{9}$ EPI from $\mathrm{CP}$ reduces absorption of fat including essential fatty acids, fat-soluble vitamins $\mathrm{A}, \mathrm{D}, \mathrm{E}$ and $\mathrm{K}$, calcium, magnesium, zinc, thiamine and folic acid. ${ }^{10}$ EPI from CP is frequently experienced as diarrhoea, abdominal discomfort and/or pain, weight loss and grossly as steatorrhoea (strictly, $>7 \mathrm{~g}$ fat in stool/24 hours). ${ }^{1}$ Intermediate and long-term malnutrition from EPI increases the incidence of osteopenia/osteoporosis, ${ }^{11}$ lowtrauma fractures, ${ }^{12}$ cardiovascular diseases ${ }^{13}$ and infections. ${ }^{6}$ These complications develop on a background of health inequalities, differences between people's health as a result of social, geographical or other factors, which are associated with less favourable outcomes from CP; foremost is malnutrition. ${ }^{14}$ Rates of alcoholism and smoking also have significant socioeconomic gradients, as do osteopenia/osteoporosis, DM and cardiovascular diseases, making health inequality an independent risk factor for the initiation and progression of $\mathrm{CP}^{4}$

Pancreatic lipase is the principal enzyme in fat digestion accounting for $90 \%$ of total lipase activity. ${ }^{9}$ Typically steatorrhoea is unlikely until pancreatic lipase output falls to $<10 \%$ of normal, ${ }^{15}$ although subclinical EPI exists in many individuals with CP. ${ }^{16}$ Large-scale Northern European studies suggest that the majority of patients with EPI secondary to $\mathrm{CP}^{17}$ or pancreatic surgery ${ }^{18}$ are undertreated, likely because of insufficient use of pancreatic enzyme replacement therapy (PERT), suboptimal scheduling in relation to meals or insufficient control of gastric acid output. The European Society for Parenteral and Enteral Nutrition 2006 Guidelines ${ }^{19}$ suggest improvement of steatorrhoea and maintenance of bodyweight as primary markers of treatment success. Such end points, however, do not detect subtler signs of malnutrition; nor do these guidelines suggest formal measures to assess improvement of steatorrhoea.
Furthermore, these end points are unsuitable as primary outcome measures for studies of PERT for EPI, particularly short-term studies. For these, accurate measures that detect alterations and/or improvements in absorption are necessary. ${ }^{13} 9{ }^{16}$ In practice, licensed enzyme replacement therapies differ greatly: granules, tablets, microspheres, minimicrospheres or capsules with enteric coating make comparisons challenging. While the European Medicines Agency has delegated regulation of PERT to national authorities, the US Food and Drug Administration (FDA) addressed these differences in 2004 (updated in 2006), ${ }^{20}$ issuing requirements for new drug applications, specifying amount, stability and efficacy. To date, six enzymes have FDA approval: Creon, Pancreaze, Pertzye, Ultrase, Viokase and Zenpep, all of porcine origin.

Questions remain as to the indications for and efficacy of PERT, including methods of assessment, formulation, dose, administration and use of acid suppression. Shafiq et $a l^{21}$ conducted a meta-analysis of PERT for CP regardless of the presence or absence of EPI. Data for weight loss and faecal fat were combined from only two studies; the authors inferred that the evidence for any beneficial role of PERT in CP was inconclusive. Waljee $e a^{22}$ and Taylor $e t a l^{23}$ combined trials in cystic fibrosis and $\mathrm{CP}$, concluding that PERT improves but does not normalise the coefficient of fat absorption (CFA) in EPI; these two systematic reviews included a total of only three placebo-controlled trials of PERT in CP, and no quantitative data were combined to determine outcomes. Three further placebo-controlled trials of PERT in CP have since been conducted, two of which were followed by open-label extensions. We have therefore conducted a systematic review of 17 randomised controlled trials (RCTs) with meta-analysis of 14 to determine whether PERT is indicated for EPI in CP, the impact of this treatment and factors contributing to optimisation of PERT. Our study is strengthened by meta-analysis of PERT versus baseline, PERT versus placebo and PERT versus PERT to provide a more rigorous evaluation, comparing CFA, coefficient of nitrogen absorption (CNA), faecal fat excretion (FFE), faecal nitrogen excretion (FNE), faecal weight, abdominal pain and GI symptoms, bodyweight, QoL and adverse events.

\section{METHODS}

\section{Search strategy}

All studies of PERT for EPI from CP were sought in Medline (PubMed), Embase, Scopus, Science Citation Index Expanded and the Cochrane Central Register of Controlled Trials between January 1966 (the first PERT study) and December 2015. The following search terms were used in all possible combinations: Chronic adj3 pancreatitis, exocrine pancreatic insufficiency, pancrea $\$$ insufficien\$; Randomized (or randomised) controlled trial.pt., controlled clinical trial. pt, randomized.ab.placebo.ab. drug therapy.fs, randomly.ab.trial.ab.group.ab; Enzymes.tw, (enzyme $\$$ adj1 (pancrea or replace $\$$ or supplement\$)).tw.(pancreatin or pancrease or pancrealipase or ultrase or cotazym or creon or kreon or theraclec or encron or protilase or lipase or hydrolase or exolipase or trigly-creidase or ALTU-135).tw; English.lg. A manual reference search of reviews and conference abstracts (2006-2015) was also undertaken.

Studies meeting all the following criteria were included: (1) in English peer-reviewed journals; (2) prospective, randomised design, investigating efficacy and safety of PERT in EPI from CP in adults (age $\geq 18$ years; including patients who had pancreatic resection for $\mathrm{CP}$ but not other indications); (3) reporting clinical outcomes of interest; and (4) only the most recent study of multiple overlapping patient populations from the same institution 
unless a prior study had higher quality. Abstracts, case reports, letters, expert opinions, editorials, reviews and non-RCTs were excluded.

Preferred Reporting Items for Systematic Reviews and Meta-analyses (PRISMA) criteria $^{24}$ were followed. Two authors (DdlI-G and WH) independently scrutinised all identified studies and reached consensus for final inclusion, with adjudication (PS) when there was disagreement.

\section{Data extraction}

Two authors (DdII-G and WH) extracted data independently using predefined standardised forms. These captured study design, quality assessment (below), baseline characteristics, health equality indicators (ethnicity, place of residence, socioeconomic background, employment/insurance status, profession, alcohol use and cigarette smoking), diagnostic criteria for CP and EPI, exclusion criteria, trial process, details of PERT and outcomes of interest.

\section{Outcomes of interest}

CFA has been used most commonly as the primary end point to assess the efficacy of PERT on EPI due to CP and cystic fibrosis in RCTs, more informative than the presence or absence of steatorrhoea. ${ }^{22} 23$ We have therefore used CFA as the primary outcome measure, calculated from fat intake $(\sim 100 \mathrm{~g} /$ day of dietary fat) and excretion (from 72 hours faecal collection) using the following equation:

$$
\begin{aligned}
\mathrm{CFA}(\%)= & {[(\text { fat intake in } \mathrm{g}-\text { fat excretion in } \mathrm{g}) / \text { fat intake in } \mathrm{g}] } \\
& \times 100
\end{aligned}
$$

CNA has been used to measure the effect of PERT on protein absorption in EPI, ignored in previous systematic reviews; ${ }^{21-23}$ CNA was calculated as follows:

$$
\begin{aligned}
\mathrm{CNA}(\%)= & {[(\text { nitrogen intake in } \mathrm{g}-\text { nitrogen excretion in } \mathrm{g})} \\
& / \text { nitrogen intake in } \mathrm{g}] \times 100
\end{aligned}
$$

Secondary outcomes included CNA, FFE, FNE, faecal weight, faecal consistency (formed/normal or soft/watery), faecal frequency (stools per day), flatulence (none/mild/moderate/severe), abdominal pain (none/mild/moderate/severe) and adverse events. When available, serum nutritional markers, diarrhoea, weight loss/gain and QoL were included.

\section{Quality assessment}

Two authors (DdII-G, WH) scored each included study using the Jadad system ${ }^{25}$ that assesses randomisation ( 0 or 1$)$, doubleblinding $(0,1$ or 2$)$, recording of dropouts and/or withdrawals $(0$ or 1$)$ and allocation concealment $(0$ or 1$)$, with a score $\geq 3$ indicative of high quality.

\section{Statistical analysis}

Means and SDs of continuous variable were used for meta-analysis, estimated ${ }^{26}$ when medians were given. If CFA and CNA were not available, these were calculated as described. If different protocols of PERT were used in any single study, average daily lipase dose was calculated in United States Pharmacopoeia (USP) units. Meta-analyses compared PERT versus baseline, PERT versus placebo or PERT versus PERT. Forest plots were generated using Review Manager V.5.3 software (Cochrane Collaboration, Oxford, UK). Continuous variables were expressed as weighted mean differences (WMD) and categorical variables as ORs with 95\% CIs. A random-effects model $^{27}$ was employed to ensure conservative estimates in meta-analyses. Heterogeneity was evaluated using $\chi^{2}$ with $\mathrm{p}<0.1$ considered significant. Statistical heterogeneity was assessed using $\mathrm{I}^{2}$ values with cut-offs of $25 \%, 50 \%$ and $75 \%$ to indicate low, moderate and high heterogeneity, respectively. ${ }^{28}$ Subgroup analyses examined studies of high quality; parallel, multicentre design; samples $\geq 40$ and Western populations. Sensitivity analyses were conducted by diagnostic criteria and inclusion of pancreatic surgery.

Meta-regression analyses assessed influence of age, gender, study design, study quality, lipase dose and publication year on summary estimates using Stata SE V.13 Software (StataCorp, Texas, USA); $\mathrm{p}<0.05$ was considered significant. Publication bias was assessed using funnel plots, ${ }^{29}$ and $p$ values generated from both CFA and FFE as per Begg and Mazumdar ${ }^{30}$ and Egger et al $;^{31} \mathrm{p}<0.10$ was considered significant.

\section{Patient and public involvement}

The research design, methods, results and their interpretation were reviewed by the NIHR Liverpool Pancreas Biomedical Research Unit Patient Advisory Group, and modifications made accordingly. The group is comprised of patients with a history of acute pancreatitis, CP or pancreatic cancer, or their carers, or interested members of the public.

\section{RESULTS}

\section{Design and quality assessment of included studies}

The PRISMA flow diagram is shown in figure $1 ; 17$ studies $^{32-48}$ were included. Study design and quality assessment are shown in table 1. There were four ${ }^{32} 334045$ conducted in the USA, nine n-39 414344 in Europe, two $^{46} 47$ in the USA and Europe, one $^{42}$ in South Africa and one ${ }^{48}$ in India. Twelve I2-37 $39-41^{39}$ 434447 had cross-over designs (two 4147 multicentre); five 3842454648 had parallel designs (three ${ }^{45} 4648$ multicentre). Five $^{41} 43 \quad 46-48$ reported sample size calculations, four ${ }^{41} 46-48$ using change of CFA values and one ${ }^{43}$ cumulative ${ }^{13} \mathrm{CO}_{2}$ recovery rate. Detailed Jadad scoring is shown in online supplementary

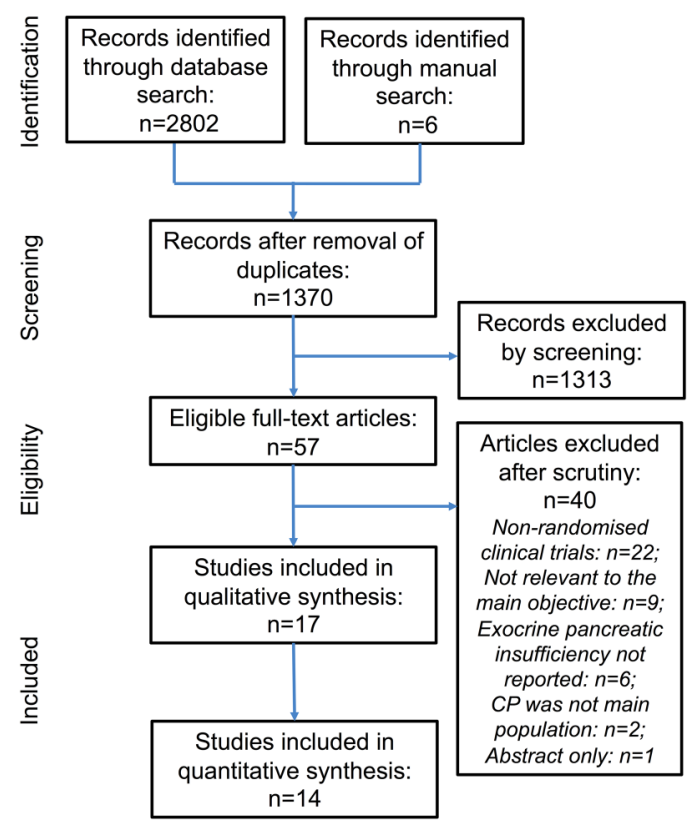

Figure 1 Preferred Reporting Items for Systematic Reviews and Meta-analyses flow chart of study selection process. CP, chronic pancreatitis. 
Table 1 Design and quality assessment of included studies

\begin{tabular}{|c|c|c|c|c|c|c|c|c|c|c|}
\hline Study & Year & Country & Study period & Design & $\begin{array}{l}\text { Single or } \\
\text { multicentre }\end{array}$ & Type* & $\begin{array}{l}\text { No. of } \\
\text { groups }\end{array}$ & $\begin{array}{l}\text { Sample size } \\
\text { calculation }\end{array}$ & $\begin{array}{l}\text { Blinding } \\
\text { method }\end{array}$ & $\begin{array}{l}\text { Jadad } \\
\text { score }\end{array}$ \\
\hline Graham $^{32}$ & 1979 & USA & NR & Cross-over & Single & PERT vs PERT & 5 & No & NR & 1 \\
\hline Dutta et $a l^{33}$ & 1983 & USA & NR & Cross-over & Single & PERT vs PERT & 3 & No & NR & 1 \\
\hline Lankisch et $a l^{34}$ & 1986 & Germany & NR & Cross-over & Single & PERT vs PERT & 3 & No & NR & 1 \\
\hline Halgreen et $a l^{35}$ & 1986 & Denmark & NR & Cross-over & Single & PERT vs placebo & 2 & No & Double & 3 \\
\hline Gouerou et al ${ }^{36}$ & 1989 & France & NR & Cross-over & Single & PERT vs PERT & 2 & No & NR & 2 \\
\hline Jørgensen et $a l^{37}$ & 1991 & Denmark & NR & Cross-over & Single & PERT vs PERT & 3 & No & NR & 1 \\
\hline Paris $^{38}$ & 1993 & France & June 1986 to June 1987 & Parallel & Single & PERT vs placebo & 2 & No & Double & 3 \\
\hline Delhaye et $a l^{39}$ & 1996 & Belgium & March 1993 to May 1994 & Cross-over & Single & PERT vs PERT & 4 & No & NR & 2 \\
\hline Opekun Jr et $a l^{40}$ & 1997 & USA & NR & Cross-over & Single & $\begin{array}{l}\text { PERT vs PERT vs } \\
\text { placebo }\end{array}$ & 4 & No & Single & 1 \\
\hline Halm et $a l^{41}$ & 1999 & Germany & NR & Cross-over & Multicentre & PERT vs PERT & 2 & Yes & Double & 4 \\
\hline O'Keefe et $a l^{42}$ & 2001 & $\begin{array}{l}\text { South } \\
\text { Africa }\end{array}$ & NR & Parallel & Single & PERT vs placebo & 2 & No & NR & 2 \\
\hline $\begin{array}{l}\text { Domínguez-Muñoz } \\
\text { et } a l^{43}\end{array}$ & 2005 & Spain & NR & Cross-over & Single & PERT vs PERT & 3 & Yes & $\begin{array}{l}\text { Not } \\
\text { possible }\end{array}$ & 2 \\
\hline Vecht et al ${ }^{44}$ & 2006 & Netherlands & NR & Cross-over & Single & PERT vs PERT & 2 & No & Double & 2 \\
\hline Safdi et $a l^{45}$ & 2006 & USA & NR & Parallel & Multicentre & PERT vs placebo & 2 & No & Double & 3 \\
\hline Whitcomb et $a l^{46}$ & 2010 & USA/Europe & April 2007 to August 2008 & Parallel & Multicentre & PERT vs placebo & 2 & Yes & Double & 5 \\
\hline Toskes et $a l^{47}$ & 2011 & USA/Europe & January 2008 to March 2009 & Cross-over & Multicentre & PERT vs PERT & 2 & Yes & Double & 3 \\
\hline Thorat et $a l^{48}$ & 2012 & India & June 2008 to May 2010 & Parallel & Multicentre & PERT vs placebo & 2 & Yes & Double & 5 \\
\hline
\end{tabular}

* Refers to comparisons of different types of PERT, different doses of the same PERT.

NR, not reported; PERT, pancreatic enzyme replacement therapy.

table S1. All seven high-quality studies $\begin{array}{lllll}35 & 38 & 41 & 45-48 & \text { were }\end{array}$ double-blinded.

\section{Baseline parameters of patients with $\mathrm{CP}$}

These are shown in online supplementary table S2; 511 patients with CP were enrolled and 477 analysed; median age was 50 years. Gender was reported in most studies (pooled 76.4\% males). Ethnicity was reported in only four. ${ }^{45-48}$ None reported residence data, smoking, socioeconomic status or profession. Five $^{41} \quad 42 \quad 46-48$ reported body mass index. Nine ${ }^{32} \quad 33 \quad 35$ $\begin{array}{llllll}36 & 39 & 40 & 44 & 48 & \text { included data on coexisting DM (pooled fre- }\end{array}$ quency $49.5 \%$ ). Patients in seven studies $32353740-4245$ did not have pancreatic surgery recorded, while the remaining studies included such patients. Ten studies ${ }^{32-36} 38-404244$ reported aetiology, with alcohol excess pooled at $89.1 \%$.

\section{Inclusion and exclusion criteria}

The diagnostic criteria for CP and EPI are shown in table 2. CP was diagnosed by imaging and/or histology in six studies, 33 36 39 46-48 imaging and/or history in seven ${ }^{35} 3738$ 41-44 and history, abnormal secretin-pancreatozymin test and/or histology in one. ${ }^{34}$ The diagnostic criteria in the remaining three studies $^{32} 4045$ were unclear. EPI was defined by FFE $>7-8 \mathrm{~g} /$ day in five, ${ }^{33} 35364143$ by FFE $>10-15 \mathrm{~g} /$ day and/or CFA $\leq 80 \%$ in nine and by faecal elastase $\leq 100 \mu \mathrm{g} / \mathrm{g}$ in one study. ${ }^{47}$ One study $^{32}$ did not report criteria for EPI and $1^{40}$ included CP patients with documented symptomatic steatorrhoea. $\operatorname{Ten}^{36} 383941-43 \quad 45-48$ reported detailed exclusion criteria.

\section{Details of trial process}

The trial process and adverse events are shown in table 2. RCTs of PERT typically had a run-in phase to scrutinise and stabilise eligible participants before treatment initiation. During run-in or washout, PERT was stopped. Six studies ${ }^{34-37} 4344$ reported a 3-15-day no-treatment run-in, while five ${ }^{38} \quad 40 \quad 45-47$ had a 5-14-day period for placebo administration before commencing the trial. Three studies ${ }^{4142} 48$ reported a 14-day run-in with the last seven days before randomisation treated by PERT. The remaining three studies ${ }^{32} 3339$ did not report a run-in phase. During treatment, PERT or placebo was used with or without a washout in between switching treatments. Daily fat intake was recorded in the majority (normally $100 \mathrm{~g} /$ day), but not in three. $^{36} 3744$ Only three 374647 reported use of a faecal dye. The equilibration time was normally 2-5 days before a 3 -day period of faecal fat collection. Adverse events were reported in six, ${ }^{36} 4145-48$ with an incidence of $11.4-42.7 \%$.

RCT study duration ranged from several days to 2 months; none assessed long-term effects of PERT, although two openlabel extension studies examined the nutritional impact of PERT over 6 months ${ }^{49}$ and 12 months. ${ }^{50}$

\section{Composition and administration schedule of PERT}

Details of PERT composition and administration schedules are shown in online supplementary table S3. Converted pancreatic lipase doses in USP units are shown in figure 2. The source of pancreatic enzymes and conversion factors is shown in online supplementary table S4. PERT formulations were granules, microtablets, microspheres and minimicrospheres with or without enteric coating. Four studies ${ }^{32-34} 36$ included noncoated and enteric-coated enzymes. Two studies ${ }^{46} 47$ used delayed release enteric-coated minimicrospheres (Creon 12000) or microspheres (Zenpep).

Delhaye's study ${ }^{39}$ found no significant differences in the efficacy of Pancrease HL and Creon 3 (both enteric-coated microspheres). Halm's study ${ }^{41}$ showed the primary outcome CFA and adverse events to be similar for Creon 10000 microspheres and minimicrospheres. Vecht's study ${ }^{44}$ found low-dose (lipase 10000 USP units tds) improved fat absorption and reduced symptoms compared with normal dose (lipase 20000 USP units tds) Pancrease when combined with strong acid inhibition (omeprazole $60 \mathrm{mg}$ ). Toskes's study ${ }^{47}$ showed low-dose (lipase $7 \times 5000$ USP units/day) and high-dose (lipase $7 \times 20000$ USP 
<smiles>C1CCCC1</smiles>

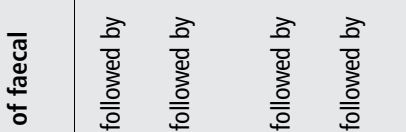

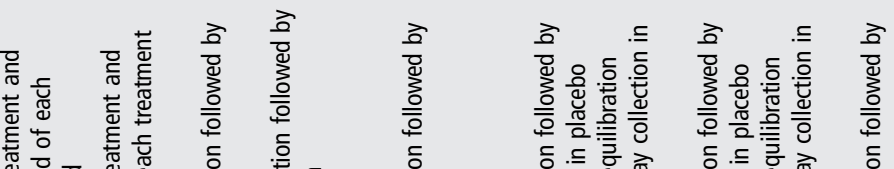

$\begin{array}{lll}\frac{N}{2} & \frac{5}{4}\end{array}$

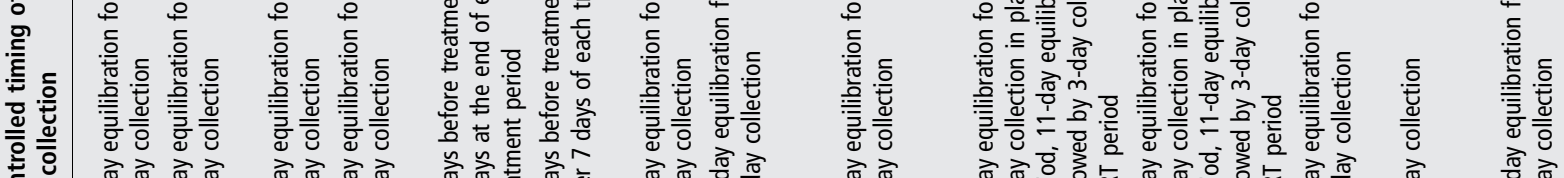

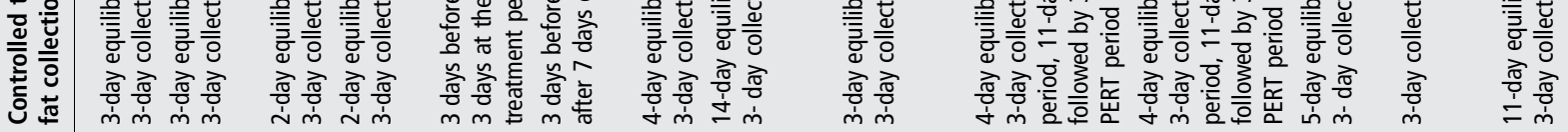

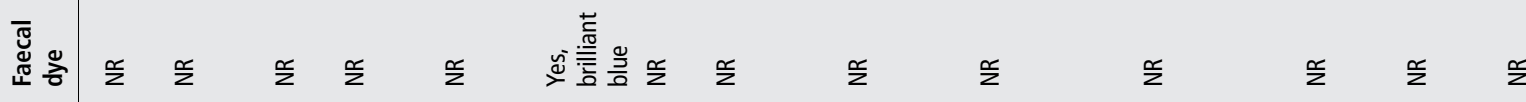

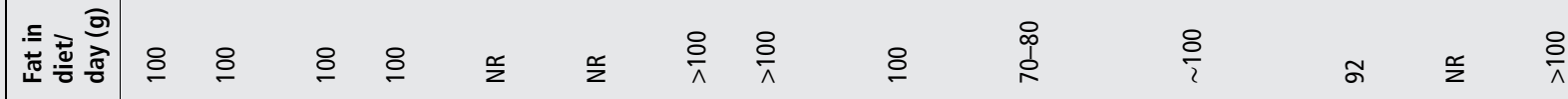

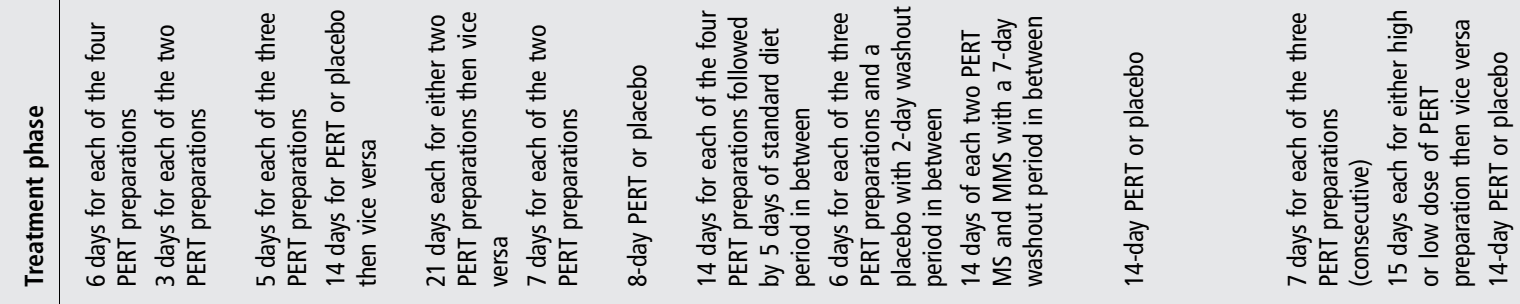

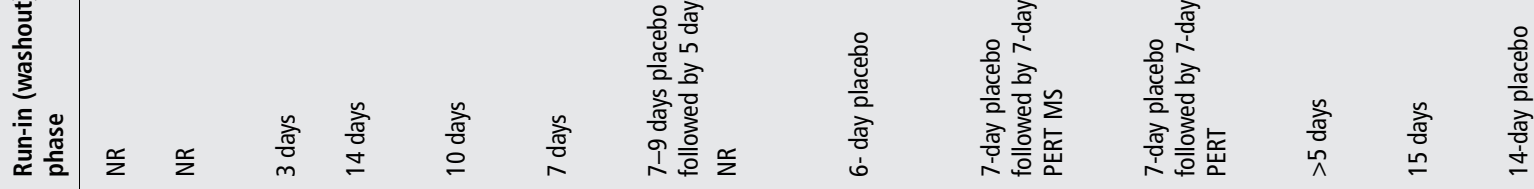
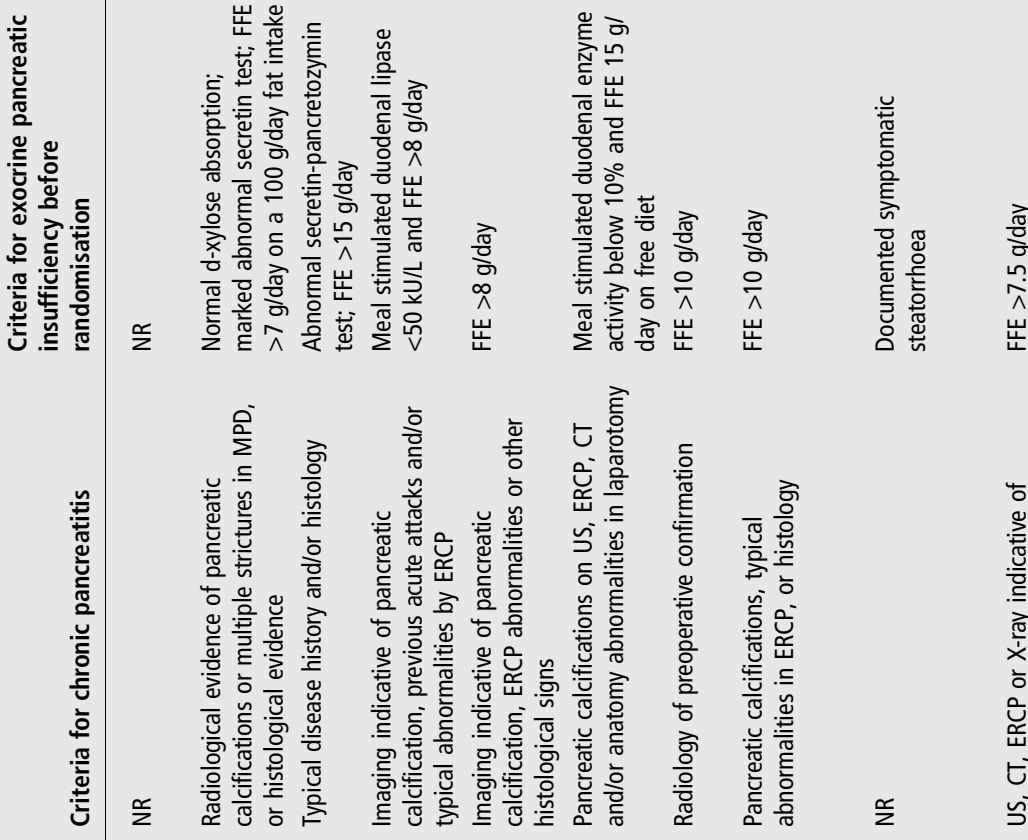

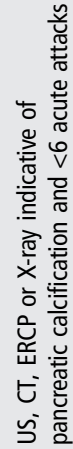

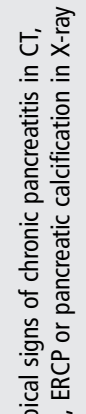

$\frac{\sqrt{0}}{5}$

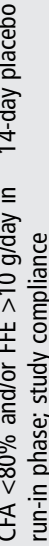



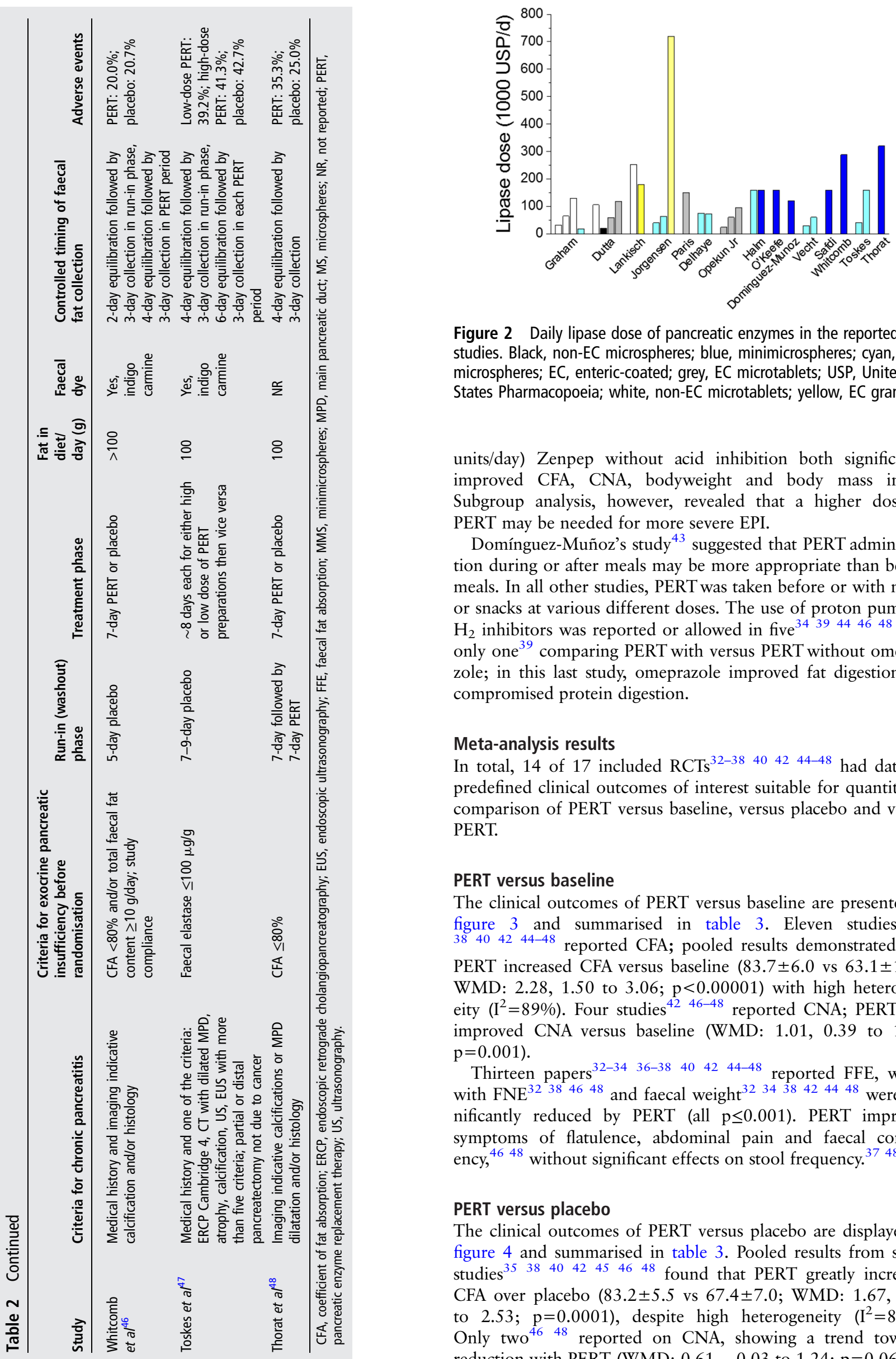

Figure 2 Daily lipase dose of pancreatic enzymes in the reported studies. Black, non-EC microspheres; blue, minimicrospheres; cyan, EC microspheres; EC, enteric-coated; grey, EC microtablets; USP, United States Pharmacopoeia; white, non-EC microtablets; yellow, EC granules.

units/day) Zenpep without acid inhibition both significantly improved CFA, CNA, bodyweight and body mass index. Subgroup analysis, however, revealed that a higher dose of PERT may be needed for more severe EPI.

Domínguez-Muñoz's study ${ }^{43}$ suggested that PERT administration during or after meals may be more appropriate than before meals. In all other studies, PERT was taken before or with meals or snacks at various different doses. The use of proton pump or $\mathrm{H}_{2}$ inhibitors was reported or allowed in five $e^{34} 39444648$ with only one ${ }^{39}$ comparing PERT with versus PERT without omeprazole; in this last study, omeprazole improved fat digestion but compromised protein digestion.

\section{Meta-analysis results}

In total, 14 of 17 included RCTs ${ }^{32-38} 404244-48$ had data on predefined clinical outcomes of interest suitable for quantitative comparison of PERT versus baseline, versus placebo and versus PERT.

\section{PERT versus baseline}

The clinical outcomes of PERT versus baseline are presented in figure 3 and summarised in table 3 . Eleven studies $^{32-34}$ $38404244-48$ reported CFA; pooled results demonstrated that PERT increased CFA versus baseline $(83.7 \pm 6.0$ vs $63.1 \pm 15.0$; WMD: $2.28,1.50$ to 3.06 ; $\mathrm{p}<0.00001$ ) with high heterogeneity $\left(\mathrm{I}^{2}=89 \%\right)$. Four studies ${ }^{42} 46-48$ reported CNA; PERT also improved CNA versus baseline (WMD: 1.01, 0.39 to 1.62; $\mathrm{p}=0.001$ ).

Thirteen papers ${ }^{32-34} \quad 36-38 \quad 40 \quad 42 \quad 44-48$ reported FFE, which with FNE ${ }^{32} 384648$ and faecal weight ${ }^{32} 3438424448$ were significantly reduced by PERT (all $\mathrm{p} \leq 0.001$ ). PERT improved symptoms of flatulence, abdominal pain and faecal consistency, ${ }^{4648}$ without significant effects on stool frequency. ${ }^{37} 48$

\section{PERT versus placebo}

The clinical outcomes of PERT versus placebo are displayed in figure 4 and summarised in table 3. Pooled results from seven studies $^{35} 384042454648$ found that PERT greatly increased CFA over placebo $(83.2 \pm 5.5$ vs $67.4 \pm 7.0$; WMD: $1.67,0.81$ to $2.53 ; \mathrm{p}=0.0001)$, despite high heterogeneity $\left(\mathrm{I}^{2}=86 \%\right)$. Only two ${ }^{46} 48$ reported on CNA, showing a trend towards reduction with PERT (WMD: $0.61,-0.03$ to $1.24 ; \mathrm{p}=0.06$ ). 
A

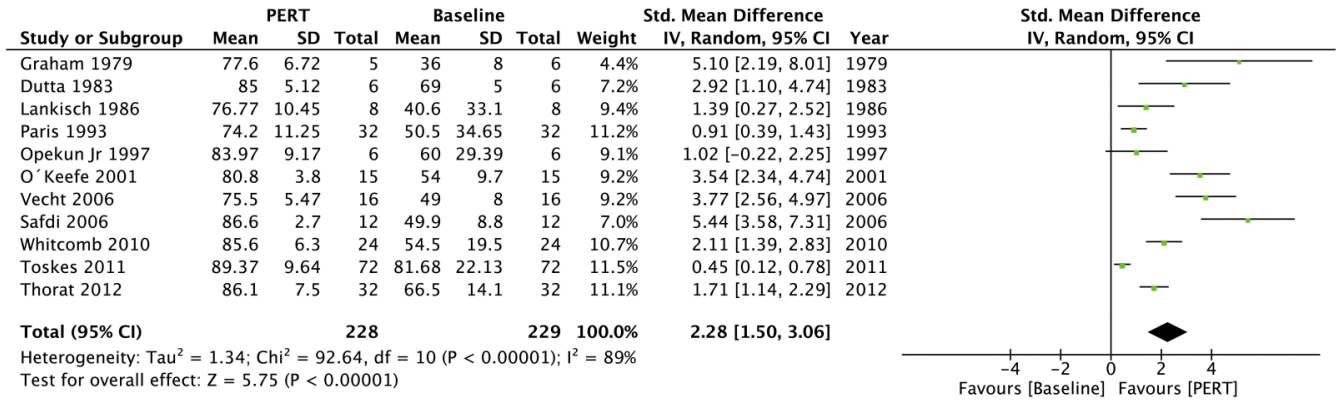

B

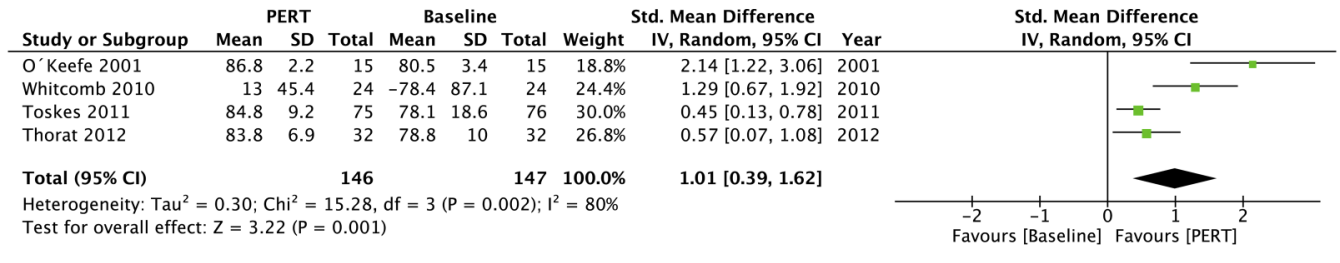

C

\begin{tabular}{|c|c|c|c|c|c|c|c|c|c|c|c|}
\hline \multirow[b]{2}{*}{ Study or Subgroup } & \multicolumn{3}{|c|}{ PERT } & \multicolumn{3}{|c|}{ Baseline } & \multicolumn{3}{|c|}{ Std. Mean Difference } & \multirow{2}{*}{\multicolumn{2}{|c|}{$\begin{array}{l}\text { Std. Mean Difference } \\
\text { IV, Random, } 95 \% \mathrm{CI}\end{array}$}} \\
\hline & Mean & SD & Total & Mean & SD & Total & Weight & IV, Random, 95\% Cl & Year & & \\
\hline Graham 1979 & 22.4 & 6.72 & 5 & 64 & 8 & 6 & $2.5 \%$ & $-5.10[-8.01,-2.19]$ & 1979 & & \\
\hline Dutta 1983 & 15 & 5.12 & 6 & 31 & 5 & 6 & $4.7 \%$ & $-2.92[-4.74,-1.10]$ & 1983 & & \\
\hline Lankisch 1986 & 23.23 & 10.45 & 8 & 59.3 & 33.1 & 8 & $7.2 \%$ & $-1.39[-2.52,-0.26]$ & 1986 & & \\
\hline Guoerou 1989 & 13.11 & 10.19 & 35 & 23.05 & 22.47 & 35 & $9.9 \%$ & $-0.56[-1.04,-0.09]$ & 1989 & - & \\
\hline Jorgensen 1991 & 18.11 & 6.63 & 15 & 25.92 & 12.11 & 15 & $8.9 \%$ & $-0.78[-1.52,-0.03]$ & 1991 & & \\
\hline Paris 1993 & 25.8 & 11.25 & 32 & 49.5 & 34.65 & 32 & $9.8 \%$ & $-0.91[-1.43,-0.39]$ & 1993 & - & \\
\hline Opekun Jr 1997 & 16.03 & 9.17 & 6 & 40 & 29.39 & 6 & $6.8 \%$ & $-1.02[-2.25,0.22]$ & 1997 & & \\
\hline O'Keefe 2001 & 20.3 & 4.3 & 15 & 48 & 10.6 & 15 & $7.1 \%$ & $-3.33[-4.49,-2.18]$ & 2001 & & \\
\hline Safdi 2006 & 18.6 & 4 & 12 & 75.1 & 18.4 & 12 & $5.8 \%$ & $-4.10[-5.60,-2.60]$ & 2006 & & \\
\hline Vecht 2006 & 18.1 & 5.08 & 16 & 36.5 & 8.4 & 16 & $7.9 \%$ & $-2.58[-3.55,-1.62]$ & 2006 & & \\
\hline Whitcomb 2010 & 14.4 & 20.8 & 24 & 45.6 & 19.5 & 24 & $9.3 \%$ & $-1.52[-2.17,-0.87]$ & 2010 & - & \\
\hline Toskes 2011 & 10.63 & 9.64 & 72 & 18.32 & 22.13 & 72 & $10.3 \%$ & $-0.45[-0.78,-0.12]$ & 2011 & - & \\
\hline Thorat 2012 & 16.2 & 9.6 & 32 & 37.3 & 17 & 34 & $9.7 \%$ & $-1.50[-2.05,-0.95]$ & 2012 & 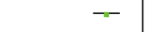 & \\
\hline Total $(95 \% \mathrm{Cl})$ & & & 278 & & & 281 & $100.0 \%$ & $-1.66[-2.19,-1.13]$ & & & \\
\hline $\begin{array}{l}\text { Heterogeneity: } \operatorname{Tau}^{2} \\
\text { Test for overall effec }\end{array}$ & $\begin{array}{l}0.68 ; \\
Z=6.1\end{array}$ & $\begin{array}{l}-h i^{2}=74 \\
6(P<0\end{array}$ & $\begin{array}{l}4.45, \mathrm{df} \\
0.00001\end{array}$ & $f=12$ & $P<0.00$ & & $l^{2}=84 \%$ & & & $\begin{array}{ccc} & 1 & 1 \\
-4 & -2 & 0 \\
\text { Favours [PERT] }\end{array}$ & $\begin{array}{c}1 \\
2 \\
\text { Favours [ }\end{array}$ \\
\hline
\end{tabular}

D

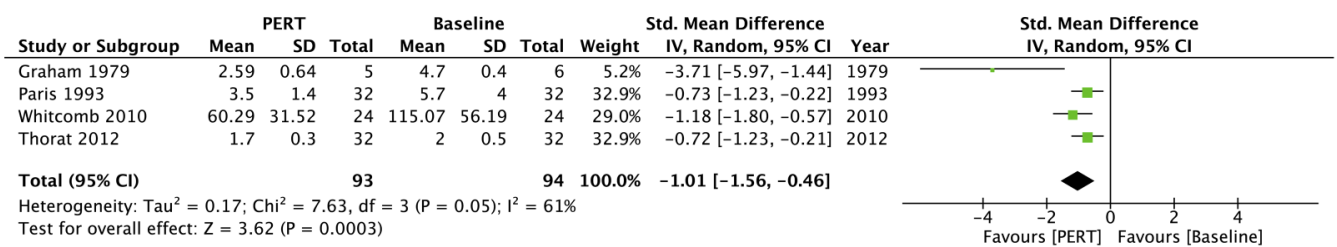

$\mathrm{E}$

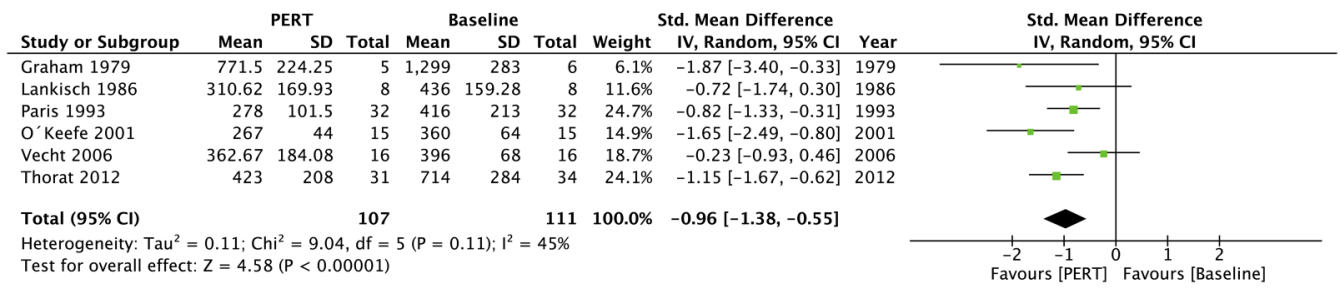

Figure 3 The pooled clinical outcomes of pancreatic enzyme replacement therapy (PERT) versus baseline. (A) coefficient of fat absorption (CFA), (B) coefficient of nitrogen absorption (CNA), (C) faecal fat excretion (FFE), (D) faecal nitrogen excretion (FNE) and (E) faecal weight. 
Table 3 Results of meta-analyses for outcomes of interest

\begin{tabular}{|c|c|c|c|c|c|c|c|}
\hline \multirow{3}{*}{$\begin{array}{l}\text { Outcomes of interest } \\
\text { PERT vs baseline }\end{array}$} & \multirow{3}{*}{ Studies, $\mathbf{n}$} & & & \multicolumn{2}{|l|}{ Effect estimate } & \multicolumn{2}{|c|}{ Heterogeneity } \\
\hline & & \multicolumn{2}{|c|}{ Patients, $\mathrm{n}$} & \multirow[t]{2}{*}{ WMD/OR $(95 \% \mathrm{Cl})$} & \multirow[t]{2}{*}{$\mathrm{p}$ Value } & \multirow[t]{2}{*}{$\mathrm{I}^{2}(\%)$} & \multirow[t]{2}{*}{$\mathrm{p}$ Value } \\
\hline & & PERT & Baseline & & & & \\
\hline CFA & 11 & 228 & 229 & 2.28 (1.50 to 3.06$)$ & $<0.00001$ & 89 & $<0.00001$ \\
\hline CNA & 4 & 146 & 147 & 1.01 (0.39 to 1.62$)$ & 0.001 & 80 & 0.002 \\
\hline FFE & 13 & 278 & 281 & $-1.66(-12.19$ to -1.13$)$ & $<0.00001$ & 84 & $<0.00001$ \\
\hline FNE & 4 & 93 & 94 & $-1.01(-1.56$ to -0.46$)$ & 0.0003 & 61 & 0.05 \\
\hline Faecal weight & 6 & 107 & 111 & $-0.96(-1.38$ to -0.55$)$ & $<0.00001$ & 45 & 0.11 \\
\hline Faecal consistency: soft & 2 & 58 & 58 & 0.47 (0.21 to 1.06$)$ & 0.07 & 63 & 0.10 \\
\hline Faecal consistency: formed/normal & 2 & 58 & 58 & 2.26 (1.05 to 4.89$)$ & 0.04 & 54 & 0.14 \\
\hline Faecal frequency & 2 & 49 & 49 & $-0.12(-0.52$ to 0.28$)$ & 0.55 & 0 & 0.87 \\
\hline Flatulence & 2 & 58 & 58 & $0.36(0.13$ to 1.02$)$ & 0.06 & 0 & 0.67 \\
\hline Abdominal pain & 2 & 58 & 58 & 0.53 (0.25 to 1.12$)$ & 0.10 & 0 & 0.62 \\
\hline PERT vs placebo & & PERT & Placebo & & & & \\
\hline CFA & 7 & 124 & 114 & 1.67 (0.81 to 2.53$)$ & 0.0001 & 86 & $<0.00001$ \\
\hline CNA & 2 & 56 & 52 & $0.61(-0.03$ to 1.24$)$ & 0.06 & 62 & 0.11 \\
\hline FFE & 7 & 124 & 114 & $-1.58(-2.39$ to -0.76$)$ & 0.0001 & 85 & $<0.00001$ \\
\hline FNE & 3 & 88 & 80 & $-0.54(-0.85$ to -0.22$)$ & 0.0007 & 40 & 0.19 \\
\hline Faecal weight & 5 & 95 & 83 & $-0.92(-1.56$ to -0.28$)$ & 0.005 & 71 & 0.007 \\
\hline Faecal consistency: soft & 2 & 58 & 55 & 0.42 (0.19 to 0.94$)$ & 0.03 & 0 & 0.89 \\
\hline Faecal consistency: formed/normal & 2 & 58 & 55 & $1.20(0.58$ to 2.52$)$ & 0.62 & 87 & 0.006 \\
\hline Faecal frequency & 3 & 70 & 69 & $-1.72(-4.00$ to 0.55$)$ & 0.14 & 96 & $<0.00001$ \\
\hline Flatulence & 2 & 58 & 55 & 1.20 (0.52 to 2.73 ) & 0.67 & 88 & 0.004 \\
\hline Abdominal pain & 2 & 58 & 55 & $0.37(0.17$ to 0.80$)$ & 0.01 & 0 & 0.85 \\
\hline Adverse event & 4 & 104 & 96 & 1.05 (0.53 to 2.07$)$ & 0.9 & 0 & 0.83 \\
\hline PERT vs PERT & & High dose & Low dose & & & & \\
\hline CFA & 4 & 88 & 90 & $0.70(-0.27$ to 1.67$)$ & 0.16 & 69 & 0.02 \\
\hline FFE & 5 & 103 & 106 & $-0.43(-1.05$ to 0.19$)$ & 0.18 & 59 & 0.05 \\
\hline Enteric-coated vs non-coated & & Coated & Non-coated & & & & \\
\hline CFA & 3 & 20 & 18 & $1.13(-1.94$ to 4.20$)$ & 0.47 & 91 & $<0.0001$ \\
\hline FFE & 4 & 55 & 53 & $-0.77(-2.66$ to 1.12$)$ & 0.42 & 89 & $<0.00001$ \\
\hline
\end{tabular}

$\mathrm{FFE}^{35} \quad 38 \quad 40 \quad 42 \quad 45 \quad 46 \quad 48 \quad \mathrm{FNE}^{38} \quad 46 \quad 48$ and faecal weight $^{35} 38404248$ were consistently attenuated by PERT compared with placebo (all $\mathrm{p} \leq 0.005$ ), as was abdominal pain $(p=0.01),{ }^{46} 48$ with a tendency to improved faecal consistency but not stool frequency and flatulence. ${ }^{45} 4648$ Pooled data from four studies 38454648 found adverse event profiles similar with PERT as placebo $(\mathrm{p}=0.9)$.

\section{PERT versus PERT}

Meta-analysis results of high versus low lipase dose regardless of delivery system are shown in figure 5A and summarised in table 3. Pooled CFA data from four studies 32334047 showed a higher CFA with high-dose PERT ( $\geq 60000$ USP units/day), although not statistically significant $(89.2 \pm 2.0$ vs $87.0 \pm 5.1$; WMD: $0.70,-0.27$ to $1.67 ; \mathrm{p}=0.16)$. Pooled FFE data from these and one further study ${ }^{37}$ were similar, with moderate heterogeneity for CFA $\left(\mathrm{I}^{2}=69 \%\right)$ and FFE $\left(\mathrm{I}^{2}=59 \%\right)$. Meta-analysis of enteric-coated microspheres versus non-coated microspheres is shown in figure $5 \mathrm{~B}$ and summarised in table 3 . Pooled CFA data from three studies ${ }^{32-34}$ showed higher CFA with enteric-coated microspheres, although not statistically significant $(85.7 \pm 4.6$ vs $75.4 \pm 10.0$; WMD: $0.70,-0.27$ to 1.67 ; $\mathrm{p}=0.16)$. Similar findings were made from four studies ${ }^{32-34} 36$ reporting FFE with small sample sizes $(n=18-55)$ and high heterogeneity.

\section{Subgroup analysis}

Subgroup analyses of PERT versus baseline for studies of highquality, parallel multicentre, sample size $\geq 40$ and in Western populations did not change primary meta-analysis results or statistical heterogeneity for CFA and FFE (table 4). Subgroup analyses of PERT versus placebo were similar, but heterogeneity was significantly reduced when sample size $\geq 40$ for CFA $\left(\mathrm{I}^{2}=86 \%\right.$ to $\left.74 \%\right)$ and FFE $\left(\mathrm{I}^{2}=85 \%\right.$ to $\left.67 \%\right)$.

\section{Sensitivity analysis}

Sensitivity analyses were performed as described in online supplementary table S5. For PERT versus baseline, the results and heterogeneity of CFA and FFE were not affected by diagnostic criteria for CP or EPI or by pancreatic surgery or by only including studies with a proper run-in phase. Heterogeneity in PERT versus placebo disappeared however for both CFA $\left(\mathrm{I}^{2}=0 \% ; \mathrm{p}=0.70\right)$ and FFE $\left(\mathrm{I}^{2}=0 \% ; \mathrm{p}=0.92\right)$ when only including $\mathrm{CP}$ defined by imaging and/or histology. 
A

CFA

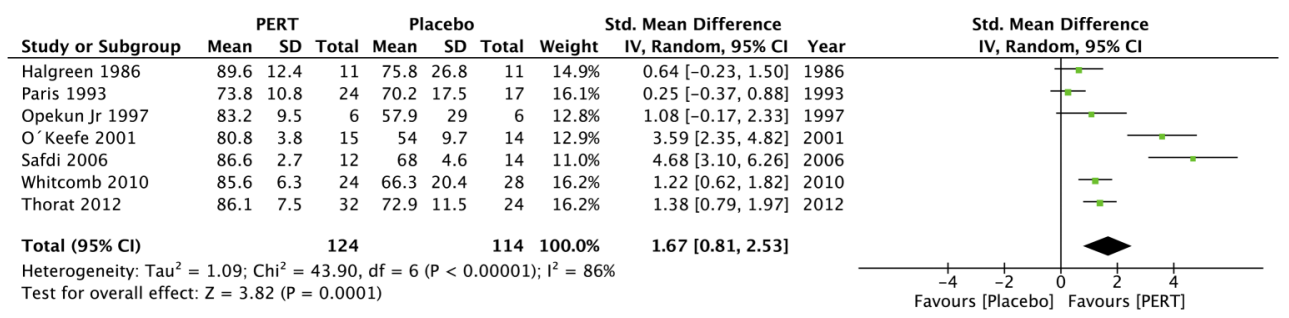

B

CNA

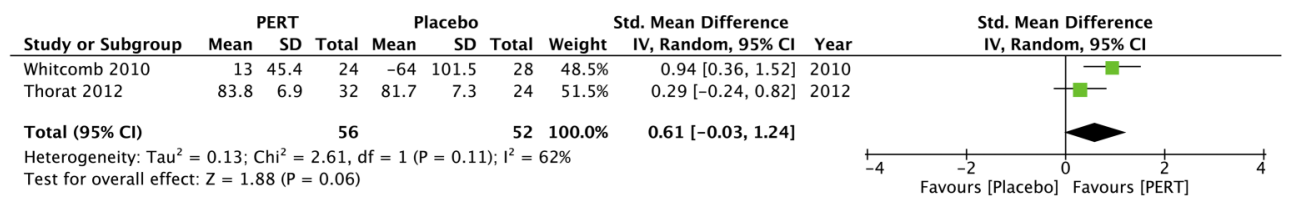

C

FFE

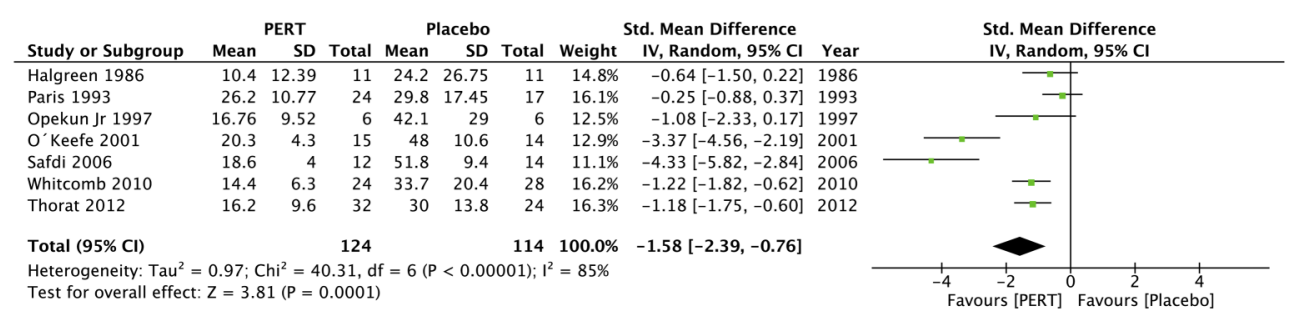

D

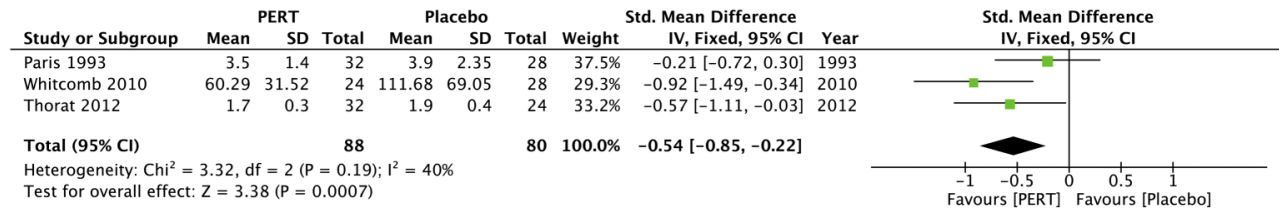

E

Fecal weight

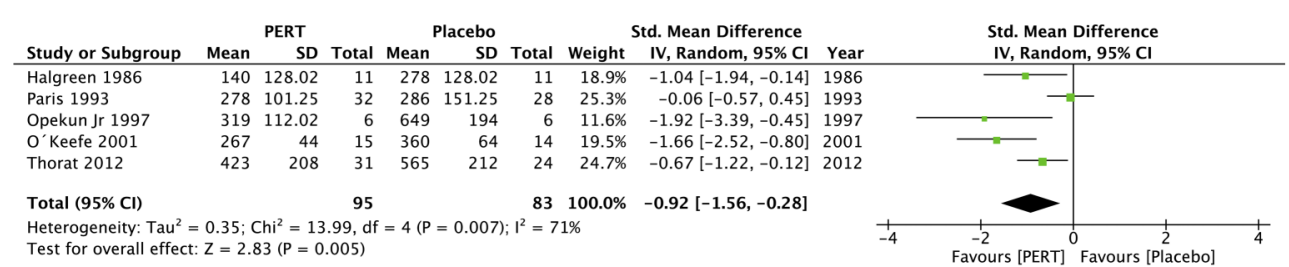

F

Adverse events

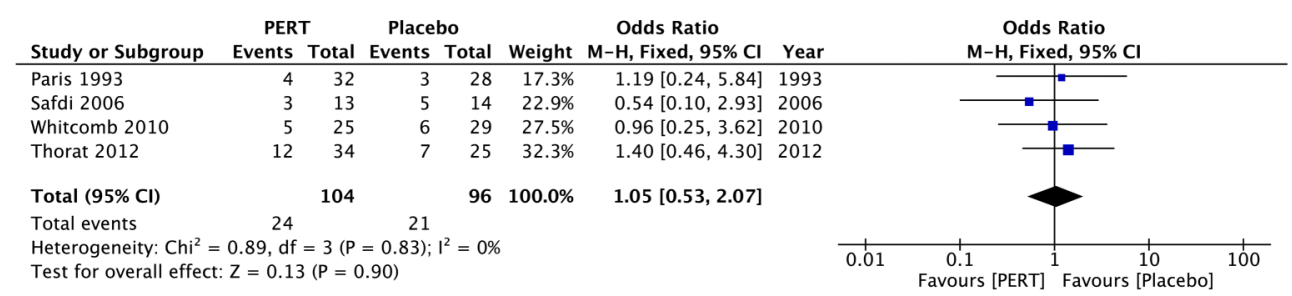

Figure 4 The pooled clinical outcomes of pancreatic enzyme replacement therapy (PERT) versus placebo. (A) coefficient of fat absorption (CFA), (B) coefficient of nitrogen absorption (CNA), (C) faecal fat excretion (FFE), (D) faecal nitrogen excretion (FNE), (E) faecal weight and (F) adverse events. 
A

CFA

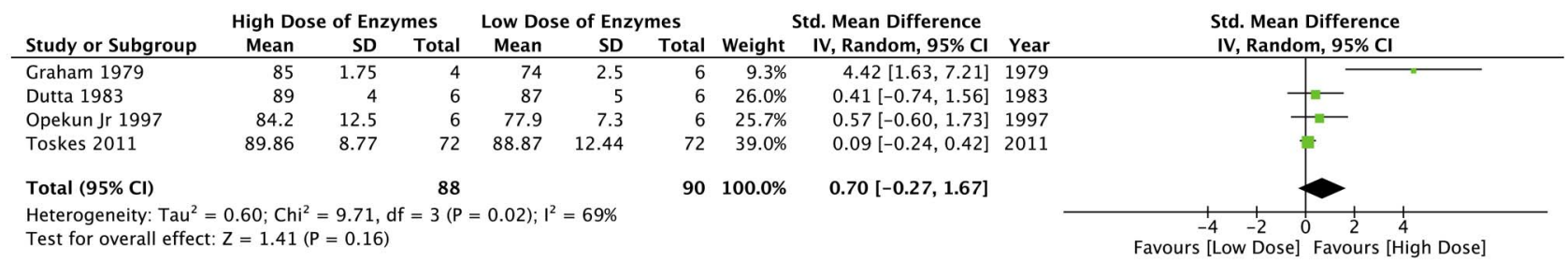

FFE

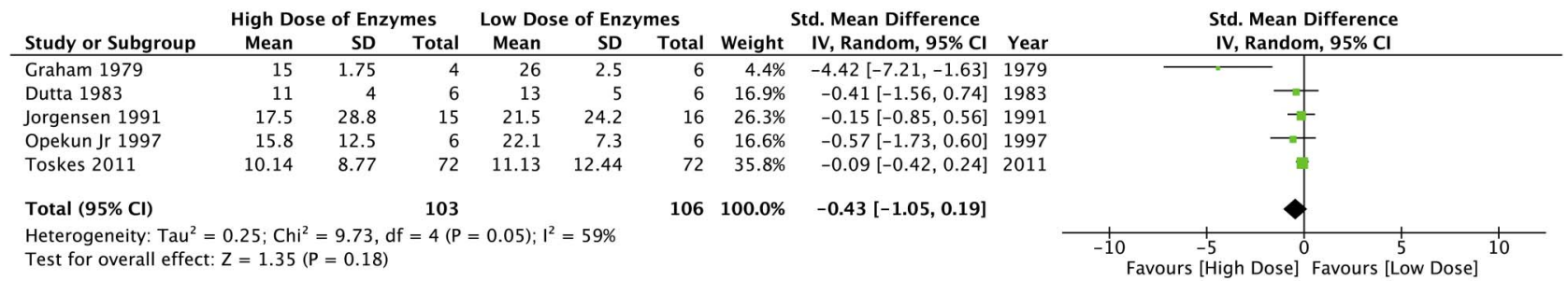

B

CFA

\begin{tabular}{|c|c|c|c|c|c|c|c|c|c|c|c|c|}
\hline \multirow[b]{2}{*}{ Study or Subgroup } & \multicolumn{3}{|c|}{ Enteric-coated } & \multicolumn{3}{|c|}{ Non-coated } & \multicolumn{3}{|c|}{ Std. Mean Difference } & \multirow{2}{*}{\multicolumn{2}{|c|}{$\begin{array}{l}\text { Std. Mean Difference } \\
\text { IV, Random, 95\% CI }\end{array}$}} & \\
\hline & Mean & SD & Total & Mean & SD & Total & Weight & IV, Random, $95 \% \mathrm{Cl}$ & Year & & & \\
\hline Graham 1979 & 80 & 2.5 & 6 & 85 & 1.75 & 4 & $33.0 \%$ & $-2.01[-3.71,-0.31]$ & 1979 & - & & \\
\hline Dutta 1983 & 89 & 4 & 6 & 81 & 4 & 6 & $34.0 \%$ & $1.85[0.40,3.29]$ & 1983 & & - & \\
\hline Lankisch 1986 & 87.4 & 2.83 & 8 & 66.5 & 7.38 & 8 & $33.0 \%$ & $3.54[1.82,5.25]$ & 1986 & & 一世- & \\
\hline Total $(95 \% \mathrm{Cl})$ & & & 20 & & & 18 & $100.0 \%$ & $1.13[-1.94,4.20]$ & & & & \\
\hline \multicolumn{10}{|c|}{$\begin{array}{l}\text { Heterogeneity: } \operatorname{Tau}^{2}=6.67 ; \mathrm{Chi}^{2}=21.60, \mathrm{df}=2(\mathrm{P}<0.0001) ; \mathrm{I}^{2}=91 \% \\
\text { Test for overall effect: } Z=0.72(\mathrm{P}=0.47)\end{array}$} & $\begin{array}{cc}-10 & -5 \\
\text { Favours [Non-coated] }\end{array}$ & Favours $[\mathrm{E}$ & $\begin{array}{r}10 \\
\text { ic-co }\end{array}$ \\
\hline
\end{tabular}

FFE

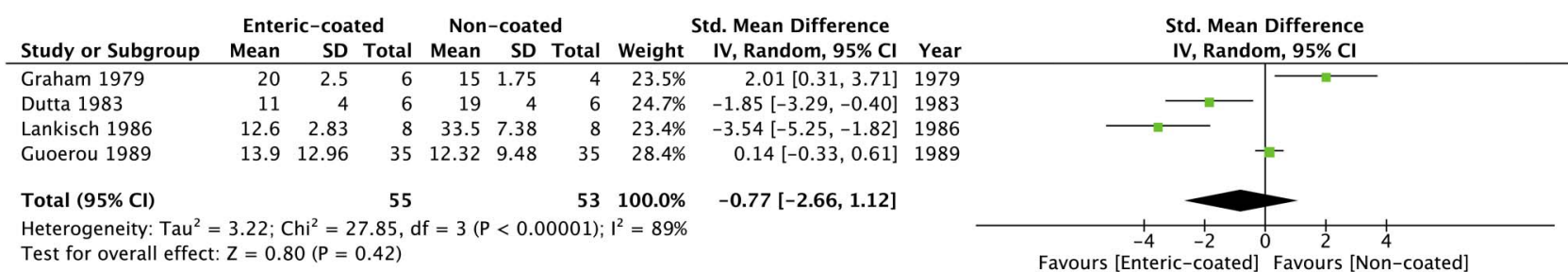

Figure 5 The pooled clinical outcomes of pancreatic enzyme replacement therapy (PERT) versus PERT. (A) coefficient of fat absorption (CFA) and faecal fat excretion (FFE) for high dose versus low dose and (B) CFA and FFE for enteric-coated versus non-coated.

\section{Meta-regression analysis}

Covariates of study design $(\mathrm{p}=0.04)$ and daily lipase dose $(\mathrm{p}=0.07)$ appeared to contribute to heterogeneity for FFE (see online supplementary table S6); age, gender, study quality and year of publication did not; limited data prevented assessment of alcohol and DM.

\section{Publication bias}

There was no significant evidence of publication bias for either CFA (see online supplementary figure S1) or FFE (see online supplementary figure S2) in PERT versus baseline, PERT versus placebo, high dose versus low dose and entericcoated versus non-coated (Begg and Egger: $p>0.10$ for all comparisons).

\section{Extension studies}

A 6-month, open-label trial ${ }^{49}$ (Creon 12000) extension of Whitcomb's study ${ }^{46}$ found PERT well tolerated, significantly improving serum nutritional parameters (retinol-binding protein, prealbumin, albumin and cholesterol) and weight, reducing faecal frequency, although no meaningful changes of QoL scores were observed. A 51-week, open-label extension trial ${ }^{50}$ from Thorat's study showed that Creon 40000 significantly improved laboratory nutritional parameters, fat and protein absorption, GI symptoms and QoL, with a favourable safety and tolerability profile.

\section{DISCUSSION}

We found PERT to improve fat and protein absorption significantly in CP, demonstrated by marked, consistent increases in CFA and CNA compared with baseline or placebo. Significant reductions in FFE, FNE, faecal weight and improvements in GI symptoms were also observed across RCTs, unchanged by subgroup, sensitivity and meta-regression analyses. Unlike in the previous Cochrane review with meta-analysis of only two studies, ${ }^{21}$ our meta-analysis of 14 RCTs demonstrates that PERT is clearly indicated in CP for EPI. Even though long-term effects on complications and mortality could not be determined, these 
Table 4 Results of subgroup analyses

\begin{tabular}{|c|c|c|c|c|c|c|c|}
\hline \multirow[b]{2}{*}{ Subgroups } & \multirow[b]{2}{*}{ Studies, $\mathbf{n}$} & \multirow{2}{*}{$\begin{array}{l}\text { Patients, } \mathrm{n} \\
\text { PERT }\end{array}$} & \multirow{2}{*}{$\begin{array}{l}\text { Patients, } \mathbf{n} \\
\text { Baseline or placebo }\end{array}$} & \multicolumn{2}{|l|}{ Effect estimate } & \multicolumn{2}{|c|}{ Heterogeneity } \\
\hline & & & & WMD/OR (95\% Cl) & $\mathrm{p}$ Value & $\mathrm{I}^{2}(\%)$ & $p$ Value \\
\hline \multicolumn{8}{|l|}{ PERT vs baseline } \\
\hline \multicolumn{8}{|l|}{ CFA } \\
\hline High-quality studies & 5 & 172 & 174 & $1.78(0.85$ to 2.70$)$ & 0.0002 & 92 & $<0.00001$ \\
\hline Parallel designed & 5 & 115 & 115 & 2.47 (1.42 to 3.52 ) & $<0.00001$ & 89 & $<0.00001$ \\
\hline Multicentre studies & 4 & 140 & 140 & 2.13 (0.84 to 3.43$)$ & 0.001 & 94 & $<0.00001$ \\
\hline Sample size $\geq 40$ & 4 & 160 & 160 & 1.26 (0.51 to 2.00$)$ & 0.001 & 88 & $<0.00001$ \\
\hline Western population & 10 & 196 & 197 & 1.17 (0.94 to 1.40$)$ & $<0.00001$ & 90 & $<0.00001$ \\
\hline \multicolumn{8}{|l|}{ FFE } \\
\hline High-quality studies & 5 & 172 & 174 & $-1.44(-2.18$ to -0.71$)$ & $<0.0001$ & 88 & $<0.00001$ \\
\hline Parallel designed & 5 & 115 & 117 & $-1.66(-2.19$ to -1.13$)$ & $<0.00001$ & 85 & $<0.00001$ \\
\hline Multicentre studies & 4 & 140 & 142 & $-1.67(-2.67$ to -0.66$)$ & 0.001 & 91 & $<0.00001$ \\
\hline Sample size $\geq 40$ & 4 & 160 & 162 & $-1.06(-1.61$ to -0.50$)$ & 0.0002 & 80 & 0.002 \\
\hline Western population & 12 & 246 & 247 & $-1.70(-2.29$ to -1.12$)$ & $<0.00001$ & 85 & $<0.00001$ \\
\hline \multicolumn{8}{|l|}{ PERT vs placebo } \\
\hline \multicolumn{8}{|l|}{ CFA } \\
\hline High-quality studies & 5 & 103 & 94 & 1.41 (0.51 to 2.31 ) & 0.002 & 86 & $<0.00001$ \\
\hline Parallel designed & 5 & 107 & 97 & 2.03 (0.90 to 3.17$)$ & 0.0005 & 90 & $<0.00001$ \\
\hline Multicentre studies & 3 & 68 & 66 & 2.16 (0.85 to 3.48$)$ & 0.001 & 88 & 0.0003 \\
\hline Sample size $\geq 40$ & 3 & 80 & 69 & 0.96 (0.28 to 1.64$)$ & 0.006 & 74 & 0.02 \\
\hline Western population & 6 & 92 & 90 & 1.77 (0.68 to 2.86 ) & 0.001 & 89 & $<0.00001$ \\
\hline \multicolumn{8}{|l|}{ FFE } \\
\hline High-quality studies & 5 & 103 & 94 & $-1.32(-2.17$ to -0.47$)$ & 0.002 & 85 & $<0.0001$ \\
\hline Parallel designed & 5 & 107 & 97 & $-1.90(-2.97$ to -0.82$)$ & 0.0005 & 90 & $<0.00001$ \\
\hline Multicentre studies & 3 & 68 & 66 & $-2.00(-3.26$ to -0.75$)$ & 0.002 & 87 & 0.0004 \\
\hline Sample size $\geq 40$ & 3 & 80 & 69 & $-0.89(-1.49$ to -0.29$)$ & 0.004 & 67 & 0.05 \\
\hline Western population & 6 & 92 & 90 & $-1.70(-2.74$ to -0.66$)$ & 0.001 & 88 & $<0.00001$ \\
\hline
\end{tabular}

CFA, coefficient of fat absorption; FFE, faecal fat excretion; PERT, pancreatic enzyme replacement therapy; WMD, weighted mean difference.

findings are similar to PERT for EPI in cystic fibrosis, 2223 which, if extrapolated, suggest long-term benefit. Although no RCT was conducted over a period longer than 2 months, two open-label extensions of up to 1 year demonstrated significant improvements in serum nutritional parameters, weight, GI symptoms and QoL. Despite PERT not wholly normalising fat absorption, driving the search for better enzymes and/or correction of other factors, ${ }^{9}$ the safety profile of PERT was comparable to placebo, also favourable in the extension studies.

Healthy nutrient digestion and absorption requires complex coordination of mechanical and enzymatic breakdown of food, a finely tuned process depending on integration of multiple upper GI functions including regulated, plentiful pancreatic exocrine and biliary secretion. ${ }^{9}$ Breakdown of fat relies on pancreatic lipase, which is highly susceptible to gastric acid; normally pancreatic bicarbonate secretion ensures intra-duodenal $\mathrm{pH}$ of 5-6 for optimal enzymatic activity, also preventing bile acid precipitation. One study found that endogenous lipase activity has to fall to $<10 \%$ of normal before steatorrhoea occurs ${ }^{15}$ and thus PERT should deliver $\geq 10 \%$ of normal lipase activity. The amount of postprandial lipase secreted in a healthy adult is estimated at between 9000 and 18000 USP units/min for up to 4 hours. $^{9}$ Therefore, delivery of at least 100000 USP units per meal (up to 400000 USP units/120000 international units in severe EPI) is required to correct EPI in adult CP; although we found a trend for higher doses to increase CFA, this increase was not statistically significant and did not fully correct malabsorption. Gastric acid inhibition can further enhance the efficacy of PERT; ${ }^{44} 5152$ we found equal efficacy of PERT at higher doses alone compared with lower doses with gastric acid suppression therapy, and an RCT not varying PERT between groups found acid suppression therapy to significantly improve fat absorption. ${ }^{52}$ Further improvement may occur if PERT is given during meals, ${ }^{43}$ corresponding with normal peak enzyme secretion some $30 \mathrm{~min}$ after food, followed by an elevated plateau. ${ }^{9}$ Future RCTs are required for definitive conclusions on PERT optimisation.

EPI is frequent but variable in CP and typically progressive over a number of years, ${ }^{1358}$ contributing to long-term complications from malnutrition. Quantification of CFA and/or FFE is rarely undertaken routinely and clinical assessments of EPI are inexact; EPI may be inferred from patient and imaging characteristics, deficiencies in fat-soluble vitamins and osteoporosis, or identified by endoscopic pancreatic function testing (normal peak pancreatic bicarbonate secretion $>80 \mathrm{mEq} / \mathrm{L}$ ). ${ }^{2}$ Lipid-soluble vitamins, retinol-binding protein, albumin and prealbumin may be useful to monitor responses to PERT. ${ }^{49} 50$ Nevertheless, once the diagnosis of CP is established and since some degree of EPI is likely, ${ }^{3}{ }^{16-18}$ PERT is the treatment of choice to reduce and/or minimise long-term malnutrition, unless pancreatic secretion is demonstrated to be normal. Support for this comes from a prospective, non-randomised, multicentre 1-year cohort study of 206 patients with EPI from CP already on PERT and 88 with newly diagnosed EPI from CP newly prescribed PERT. ${ }^{53}$ EPI was identified by maldigestion, diarrhoea/ steatorrhoea, weight loss, meteorism, dyspepsia, recurrent pain, nausea and vomiting. PERT was associated with significant reductions in recurrent abdominal pain, GI symptoms and GI 
QoL index (all $\mathrm{p}<0.001$ ) in both cohorts, although uncertainty remains as to how PERT reduces intestinal and/or pancreatic pain.

Despite use of the more conservative random-effects model, we found significant heterogeneity between studies. Subgroup analyses, however, did not alter estimates of the effect of PERT versus baseline or placebo on CFA and FFE, nor estimates of heterogeneity, although restriction of analysis to larger studies reduced heterogeneity. Sensitivity analyses did not alter estimates for CFA and FFE, but heterogeneity was abolished for FFE in PERT versus placebo when CP was diagnosed by imaging and/or histology criteria. The heterogeneity identified highlights the need for greater international consensus on the definition and diagnosis of $\mathrm{CP}^{54}$

Access to medical expertise, compliance, diet and lifestyle is heavily influenced by health inequalities. ${ }^{4}$ Proxy indicators, notably alcohol usage and cigarette smoking, are themselves independently associated with progression of $\mathrm{CP}$ and nutrient deprivation. ${ }^{4}$ In our study, $76.4 \%$ of patients were male and $89.1 \%$ of patients had alcohol-associated CP, but none of the RCTs reported measures of smoking, residence, socioeconomic or employment status, diet or comorbidity. As genetic factors and smoking have become increasingly recognised in CP progression, ${ }^{2}{ }^{3}$ health inequalities should be addressed in future studies of PERT to increase the applicability of findings to all patients with $\mathrm{CP}$.

Acknowledgements The authors thank the University Hospital of Santiago de Compostela, Spain, for supporting Ddll-G during a 6-month full-time fellowship in the NIHR Liverpool Pancreas BRU.

Collaborators The Members of the NIHR Pancreas Biomedical Research Unit Patient Advisory Group: Graham Cameron, Kirsty Donaldson, Georgia Jones, John Lancaster, Amy Lucas, Karen Manby, Tor McLaren (BRU Steering Committee), Catherine Rodgers, Jason Rodgers, William Swindlehurst (Chair), Neil Symon, Douglas Warrington, Mary Whitby.

Contributors Ddll-G and WH are co-first authors. RS and JED-M conceived, designed and supervised the study, and obtained funding. DdII-G, WH, PS, IB-R, JG-L, GP-R, RM and QMN acquired, analysed and interpreted the data. Ddll-G, WH and RS wrote the paper; JED-M and NIHR BRU PAG undertook critical revision of the manuscript for important intellectual content.

Funding This work was funded by the University Hospital of Santiago de Compostela, Spain (DdIl-G, IB-R, JG-L, GP-R, JED-M), Royal College of Surgeons of England (PS) and the Biomedical Research Unit funding scheme of the National Institute for Health Research (WH, RM, QMN, RS). RS is an NIHR Senior Investigator.

Competing interests JED-M has provided consultancy to and received financial support from Abbott (Mylan) for lecture fees and travel expenses; RS has provided consultancy to Abbott (Mylan).

Provenance and peer review Not commissioned; externally peer reviewed.

Data sharing statement Upon publication raw data from individual studies will be made available by the corresponding author to interested researchers requesting data for bona fide scientific purposes.

Open Access This is an Open Access article distributed in accordance with the terms of the Creative Commons Attribution (CC BY 4.0) license, which permits others to distribute, remix, adapt and build upon this work, for commercial use, provided the original work is properly cited. See: http://creativecommons.org/licenses/ by/4.0/

\section{REFERENCES}

1 Forsmark CE. Management of chronic pancreatitis. Gastroenterology 2013:144:1282-91.e3.

2 Conwell DL, Lee LS, Yadav D, et al. American Pancreatic Association Practice Guidelines in Chronic Pancreatitis: evidence-based report on diagnostic guidelines. Pancreas 2014;43:1143-62.

3 Lévy P, Domínguez-Muñoz E, Imrie C, et al. Epidemiology of chronic pancreatitis: burden of the disease and consequences. United European Gastroenterol $J$ 2014:2:345-54.

4 Yadav D, Whitcomb DC. The role of alcohol and smoking in pancreatitis. Nat Rev Gastroenterol Hepatol 2010;7:131-45.
5 Wehler M, Nichterlein R, Fischer B, et al. Factors associated with health-related quality of life in chronic pancreatitis. Am J Gastroenterol 2004;99:138-46.

6 Yadav D, Timmons L, Benson JT, et al. Incidence, prevalence, and survival of chronic pancreatitis: a population-based study. Am J Gastroenterol 2011;106:2192-9.

7 Peery AF, Crockett SD, Barritt AS, et al. Burden of gastrointestinal, liver, and pancreatic diseases in the United States. Gastroenterology 2015;149:1731-41.e3.

8 Hall TC, Garcea G, Webb MA, et al. The socio-economic impact of chronic pancreatitis: a systematic review. J Eval Clin Pract 2014;20:203-7.

9 Keller J, Layer P. Human pancreatic exocrine response to nutrients in health and disease. Gut 2005;54(Suppl 6):vi1-28.

10 Duggan SN, Smyth ND, O'Sullivan M, et al. The prevalence of malnutrition and fat-soluble vitamin deficiencies in chronic pancreatitis. Nutr Clin Pract 2014;29:348-54.

11 Duggan SN, Smyth ND, Murphy A, et al. High prevalence of osteoporosis in patients with chronic pancreatitis: a systematic review and meta-analysis. Clin Gastroenterol Hepatol 2014;12:219-28.

12 Tignor AS, Wu BU, Whitlock TL, et al. High prevalence of low-trauma fracture in chronic pancreatitis. Am J Gastroenterol 2010;105:2680-6.

13 Gullo L, Tassoni U, Mazzoni G, et al. Increased prevalence of aortic calcification in chronic pancreatitis. Am J Gastroenterol 1996;91:759-61.

14 Stratton RJ. Malnutrition: another health inequality? Proc Nutr Soc 2007;66:522-9.

15 DiMagno EP, Go VL, Summerskill WH. Relations between pancreatic enzyme outputs and malabsorption in severe pancreatic insufficiency. $N$ Eng/ J Med 1973;288:813-15.

16 Keller J, Brückel S, Jahr C, et al. A modified (1)(3)C-mixed triglyceride breath test detects moderate pancreatic exocrine insufficiency. Pancreas 2011:40:1201-5.

17 Sikkens EC, Cahen DL, van Eijck C, et al. Patients with exocrine insufficiency due to chronic pancreatitis are undertreated: a Dutch national survey. Pancreatology 2012;12:71-3.

18 Sikkens EC, Cahen DL, van Eijck C, et al. The daily practice of pancreatic enzyme replacement therapy after pancreatic surgery: a northern European survey: enzyme replacement after surgery. J Gastrointest Surg 2012;16:1487-92.

19 Meier $\mathrm{R}$, Ockenga J, Pertkiewicz $\mathrm{M}$, et al. ESPEN guidelines on enteral nutrition: pancreas. Clin Nutr 2006:25:275-84.

20 Guidance for industry exocrine pancreatic insufficiency drug products - submitting NDAs. U.S. Department of Health and Human Services Food and Drug Administration Center for Drug Evaluation and Research (CDER). April 2006. http:// www.fda.gov/downloads/drugs/guidancecomplianceregulatoryinformation/guidances/ ucm071651.pdf

21 Shafiq N, Rana S, Bhasin D, et al. Pancreatic enzymes for chronic pancreatitis. Cochrane Database Syst Rev 2009:CD006302.

22 Waljee AK, Dimagno MJ, Wu BU, et al. Systematic review: pancreatic enzyme treatment of malabsorption associated with chronic pancreatitis. Aliment Pharmacol Ther 2009;29:235-46.

23 Taylor JR, Gardner TB, Waljee AK, et al. Systematic review: efficacy and safety of pancreatic enzyme supplements for exocrine pancreatic insufficiency. Aliment Pharmacol Ther 2010:31:57-72.

24 Moher D, Liberati A, Tetzlaff J, et al. Preferred reporting items for systematic reviews and meta-analyses: the PRISMA statement. Ann Intern Med 2009;151:264-9, W64.

25 Jadad AR, Moore RA, Carroll D, et al. Assessing the quality of reports of randomized clinical trials: is blinding necessary? Control Clin Trials 1996;17:1-12.

26 Hozo SP, Djulbegovic B, Hozo I. Estimating the mean and variance from the median, range, and the size of a sample. BMC Med Res Methodol 2005;5:13.

27 DerSimonian R, Laird N. Meta-analysis in clinical trials. Control Clin Trials 1986; 7:177-88

28 Higgins JP, Thompson SG, Deeks JJ, et al. Measuring inconsistency in meta-analyses. BMJ 2003;327:557-60.

29 Sterne JA, Egger M, Smith GD. Systematic reviews in health care: investigating and dealing with publication and other biases in meta-analysis. BMJ 2001;323:101-5.

30 Begg CB, Mazumdar M. Operating characteristics of a rank correlation test for publication bias. Biometrics 1994:50:1088-101.

31 Egger M, Davey Smith G, Schneider M, et al. Bias in meta-analysis detected by a simple, graphical test. BMJ 1997:315:629-34.

32 Graham DY. An enteric-coated pancreatic enzyme preparation that works. Dig Dis Sci 1979:24:906-9.

33 Dutta SK, Rubin J, Harvey J. Comparative evaluation of the therapeutic efficacy of a pH-sensitive enteric coated pancreatic enzyme preparation with conventional pancreatic enzyme therapy in the treatment of exocrine pancreatic insufficiency. Gastroenterology 1983:84:476-82.

34 Lankisch PG, Lembcke B, Göke B, et al. Therapy of pancreatogenic steatorrhoea: does acid protection of pancreatic enzymes offer any advantage? Z Gastroenterol 1986:24:753-7.

35 Halgreen $H$, Pedersen NT, Worning $H$. Symptomatic effect of pancreatic enzyme therapy in patients with chronic pancreatitis. Scand J Gastroenterol 1986;21:104-8.

36 Gouerou H, Dain MP, Parrondo I, et al. Alipase versus nonenteric-coated enzymes in pancreatic insufficiency. A French multicenter crossover comparative study. Int J Pancreatol 1989;5(Suppl):45-50 
37 Jørgensen $B B$, Pedersen NT, Worning $H$. Monitoring the effect of substitution therapy in patients with exocrine pancreatic insufficiency. Scand J Gastroenterol 1991;26:321-6.

38 Paris JC. A multicentre double-blind placebo-controlled study of the effect of a pancreatic enzyme formulation (Panzytrat 25000) on impaired lipid digestion in adults with chronic pancreatitis. Drug Investigation 1993;5:229-37.

39 Delhaye M, Meuris S, Gohimont AC, et al. Comparative evaluation of a high lipase pancreatic enzyme preparation and a standard pancreatic supplement for treating exocrine pancreatic insufficiency in chronic pancreatitis. Eur J Gastroenterol Hepatol 1996:8:699-703.

40 Opekun AR Jr, Sutton FM Jr, Graham DY. Lack of dose-response with Pancrease MT for the treatment of exocrine pancreatic insufficiency in adults. Aliment Pharmacol Ther 1997;11:981-6.

41 Halm U, Löser C, Löhr M, et al. A double-blind, randomized, multicentre, crossover study to prove equivalence of pancreatin minimicrospheres versus microspheres in exocrine pancreatic insufficiency. Aliment Pharmacol Ther 1999;13:951-7.

42 O'Keefe SJ, Cariem AK, Levy M. The exacerbation of pancreatic endocrine dysfunction by potent pancreatic exocrine supplements in patients with chronic pancreatitis. J Clin Gastroenterol 2001;32:319-23.

43 Domínguez-Muñoz JE, Iglesias-García J, Iglesias-Rey M, et al. Effect of the administration schedule on the therapeutic efficacy of oral pancreatic enzyme supplements in patients with exocrine pancreatic insufficiency: a randomized, three-way crossover study. Aliment Pharmacol Ther 2005;21:993-1000.

44 Vecht J, Symersky T, Lamers CB, et al. Efficacy of lower than standard doses of pancreatic enzyme supplementation therapy during acid inhibition in patients with pancreatic exocrine insufficiency. J Clin Gastroenterol 2006:40:721-5

45 Safdi M, Bekal PK, Martin S, et al. The effects of oral pancreatic enzymes (Creon 10 capsule) on steatorrhea: a multicenter, placebo-controlled, parallel group trial in subjects with chronic pancreatitis. Pancreas 2006;33:156-62.
46 Whitcomb DC, Lehman GA, Vasileva G, et al. Pancrelipase delayed-release capsules (CREON) for exocrine pancreatic insufficiency due to chronic pancreatitis or pancreatic surgery: a double-blind randomized trial. Am J Gastroentero/ 2010;105:2276-86.

47 Toskes PP, Secci A, Thieroff-Ekerdt R, et al. Efficacy of a novel pancreatic enzyme product, EUR-1008 (Zenpep), in patients with exocrine pancreatic insufficiency due to chronic pancreatitis. Pancreas 2011;40:376-82.

48 Thorat V, Reddy N, Bhatia S, et al. Randomised clinical trial: the efficacy and safety of pancreatin enteric-coated minimicrospheres (Creon 40000 MMS) in patients with pancreatic exocrine insufficiency due to chronic pancreatitis - a double-blind, placebo-controlled study. Aliment Pharmacol Ther 2012;36:426-36.

49 Gubergrits N, Malecka-Panas E, Lehman GA, et al. A 6-month, open-label clinica trial of pancrelipase delayed-release capsules (Creon) in patients with exocrine pancreatic insufficiency due to chronic pancreatitis or pancreatic surgery. Aliment Pharmacol Ther 2011;33:1152-61.

50 Ramesh H, Reddy N, Bhatia S, et al. A 51-week, open-label clinical trial in India to assess the efficacy and safety of pancreatin 40000 enteric-coated minimicrospheres in patients with pancreatic exocrine insufficiency due to chronic pancreatitis. Pancreatology 2013;13:133-9.

51 Dominguez-Muñoz JE, Iglesias-García J, Iglesias-Rey M, et al. Optimising the therapy of exocrine pancreatic insufficiency by the association of a proton pump inhibitor to enteric coated pancreatic extracts. Gut 2006;55:1056-7.

52 Bruno MJ, Rauws EA, Hoek FJ, et al. Comparative effects of adjuvant cimetidine and omeprazole during pancreatic enzyme replacement therapy. Dig Dis Sci 1994:39:988-92.

53 D'Haese JG, Ceyhan GO, Demir IE, et al. Pancreatic enzyme replacement therapy in patients with exocrine pancreatic insufficiency due to chronic pancreatitis: a 1-year disease management study on symptom control and quality of life. Pancreas 2014;43:834-41.

54 Whitcomb DC, Frulloni L, Garg P, et al. Chronic pancreatitis: an international draft consensus proposal for a new mechanistic definition. Pancreatology 2016;16:218-24 